\title{
Determination of Metformin at Metal-Organic Framework (Cu-BTC) Nanocrystals/Multi-walled Carbon Nanotubes Modified Glassy Carbon Electrode
}

\author{
Mojtaba Hadi, Haniyeh Poorgholi and Hossein Mostaanzadeh \\ Department of Chemistry, Faculty of Sciences, University of Qom, Qom, Iran.
}

Received 2 February 2016, revised 10 March 2016, accepted 8 April 2016.

\begin{abstract}
Glassy carbon (GC) electrode modified with Cu-based metal-organic frameworks (Cu-BTC, BTC = 1,3,5-benzenetricarboxylate) and multi-walled carbon nanotubes (CNTs) composites was developed. The Cu-BTCs were synthesized by two methods, traditional hydrothermal and ultrasonic irradiation methods. It was found that the Cu-BTC that was synthesized by the latter method, with mean crystallite sizes in the nanometers range, showed a higher impact on enhancing the electrocatalytic activity of the modified electrode toward the electro-oxidation of metformin compared to that synthesized with the former method with a larger crystallite size of micrometer-scale. The morphological characteristics of Cu-BTCs and Cu-BTC nanocrystals/CNTs modified GC electrode surface were characterized by scanning electron microscopy. The modified electrode showed excellent response of oxidation current for the determination of metformin. Under optimum conditions, the peak current showed good linearity with concentrations in the range of $0.5 \mu \mathrm{M}$ to $25 \mu \mathrm{M}$ and a detection limit of $0.12 \mu \mathrm{M}$, as well as good repeatability. The Cu-BTC nanocrystals/CNTs modified GC electrode was applied successfully to determine metformin in pharmaceutical samples with good accuracy.
\end{abstract}

KEYWORDS

Metal-organic framework, carbon nanotube, modified glassy carbon electrode, metformin, electroanalytical determination.

\section{Introduction}

Metformin is an antidiabetic medication and is considered as a first-line drug choice for the treatment of type 2 diabetes. ${ }^{1}$ Developing sensitive, simple and fast methods for measurement of metformin in biological samples is needed for pharmacokinetic and pharmacological studies. Several methods have been proposed for its quantitative analysis including capillary electrophoresis, ${ }^{2,3}$ chromatography, ${ }^{4}{ }^{13}$ NMR spectrometry, ${ }^{14}$ spectrophotometry, ${ }_{1}^{15}{ }_{2}^{24}$ conductometry ${ }^{25}$ and IR spectrometry. ${ }^{26}$ However, some of these methods suffer from disadvantages such as long analysis time, complicated sample preparation procedures, and very costly instrumentation. Electroanalytical-based methods for detection of metformin can be proposed as a simple and inexpensive alternative to the above methodologies. The electroanalytical methods can provide more sensitivity and reduces analysis time so that continuous real-time analysis can be performed. Nevertheless, direct electro-oxidation of metformin at conventional unmodified electrodes is usually limited by the slow electron-transfer kinetics, electrode surface fouling and high overpotentials. To solve these problems, modified electrodes have been applied for the detection of metformin. For example, pyrogallol, ${ }^{27} \mathrm{BiVO}_{4}{ }^{28}$ copperloaded charcoal $^{29}, \mathrm{Cu}$-based coordination polymer/carbon nanotubes (CNTs), ${ }^{30}$ and nickel oxide nanotubes/carbon microparticles ${ }^{31}$ have been mixed with carbon paste to prepare modified electrodes for metformin detection. In the present study, a Cu-based metal-organic framework (MOF) has been utilized as an efficient electrode modifier for metformin detection. Literature survey shows that very few attempts have been

* To whom correspondence should be addressed. E-mail: m.hadi@qom.ac.ir made to metformin detection using voltammetric techniques. ${ }^{28-31}$ Thus, the aim of this work was to develop a new, simple and sensitive electroanalytical method for the determination of metformin in pharmaceutical formulations. The electrochemical sensor was a GC electrode simply modified with a $\mathrm{Cu}$-based MOF (Cu-BTC) nanocrystals/multi-walled CNTs hybrid nanostructure.

In the past decade, CNTs have become the focus of great interest on the fabrication of chemically modified electrodes due to their large surface area, unique architecture, and remarkable mechanical and electrical properties. ${ }^{32,33}$ Their large surface area could increase the electron transfer rate and produce higher response sensitivity due to its high adsorption capability to target analyte molecules. Also, the porous nature of the drop-cast fabricated CNT films may provide a supportive scaffold for the uniform deposition of the MOF nanocrystals.

From the last decade, MOFs that are constructed of metal ions coordinated to organic linkers to form one-, two-, or threedimensional highly ordered porous structures have attracted much attention due to their high accessible surface area and porosity and have been applied in a variety of fields such as gas separation, sensors, ion exchange, catalysis and supercapacitors. ${ }^{35}$ Due to their low electronic conductivity, there are only a few studies on applying MOFs barely as electrode modifiers in electroanalysis. ${ }^{36,37}$ More recently, MOF-based multi-components materials have been proposed, in which the combination of MOFs and highly conductive nanostructured materials provides added conductivity and electrocatalytic ability against target analytes. For example, immobilization of Au-SH-SiO ${ }_{2}$ nanoparticles on $\mathrm{Cu}$-based MOF for l-cysteine ${ }^{38}$ and hydrazine ${ }^{39}$ detection, immobilization of $\mathrm{Cu}$-based MOF on multi-walled CNTs for $\mathrm{H}_{2} \mathrm{O}_{2}$ sensing, ${ }^{40}$ carbon-functionalized Al-based MOF 
for dopamine detection, ${ }^{41} \mathrm{Cu}$-based MOF-loaded on macroporous carbon for $\mathrm{NADH}$ and $\mathrm{H}_{2} \mathrm{O}_{2}$ sensing, ${ }^{42}$ combination of $\mathrm{Cu}$-based MOF and graphene oxides for acetaminophen and dopamine ${ }^{43}$ detection, $\mathrm{Cu}$-based MOF/single-walled CNTs modified electrode for simultaneous determination of hydroquinone and catechol, ${ }^{44}$ and $\mathrm{Cu}$-based MOF/multi-walled CNTs modified electrode for determination of lead ${ }^{45}$ have been proposed. Recently, a review article has been also published relating to the use of MOF materials as electrode modifiers for electroanalytical sensing applications. ${ }^{46}$

MOFs have been routinely synthesized by hydro/solvothermal methods. Recently, ultrasonic irradiation reaction methods have been also introduced as facile, rapid and inexpensive route toward the synthesis of these compounds. ${ }^{47}$ The former methods usually yield large MOF crystals whereas the latter methods yield MOFs as nanocrystalline powders. ${ }^{47}$ In the present study, the $\mathrm{Cu}$-BTC was synthesized by both the methods and it has been shown that the Cu-BTC prepared by ultrasonic irradiation synthesis with nanosized crystals provides higher electrocatalytic performance compared to that synthesized with hydrothermal method with a larger crystallite size. The morphological characteristics of the synthesized Cu-BTCs and the $\mathrm{Cu}-\mathrm{BTC} / \mathrm{CNTs}$ modified GC electrode were investigated by scanning electron microscopy (SEM). The results demonstrated that the Cu-BTC nanocrystals/CNTs modified GC electrode has good performance towards metformin detection with a high sensitivity and a wide linear range.

\section{Experimental}

\subsection{Materials}

All chemicals were of analytical grade and were used as received, without further purification. The standard metformin hydrochloride (Sigma) solutions were prepared freshly before use. Multi-walled CNT (with the outside diameter of 5-15 nm and length of about $50 \mu \mathrm{m}$ ) was purchased from US Research Nanomaterials, Inc.

\subsection{Apparatus}

Voltammetric experiments were performed using a Sama potentiostat/galvanostat model 500 (Isfahan, Iran). A graphite rod $(0.5 \mathrm{~cm} \times 2 \mathrm{~cm})$ served as an auxiliary electrode and an $\mathrm{Ag} / \mathrm{AgCl}(3 \mathrm{M} \mathrm{KCl})$ electrode was used as a reference electrode. Synthesis of the Cu-BTC nanocrystals was performed in a Rocker ultrasonic bath (Soner 203). The SEM images were obtained with a Hitachi S4160 (Cold Field Emission) scanning electron microscope. Prior to SEM examination, the SEM samples were coated with a thin film of Au in a coating machine to enhance their conductivity.

\subsection{Synthesis of Cu-BTCs}

\subsubsection{Synthesis of Cu-BTC Microcrystals}

$\mathrm{Cu}-\mathrm{BTC}$ microcrystals was synthesized using a similar method to that reported by J. Gascon et al. ${ }^{48}$ Briefly, $0.292 \mathrm{~g} \mathrm{Cu}\left(\mathrm{NO}_{3}\right)_{2}$ $3 \mathrm{H}_{2} \mathrm{O}$ were added to $5 \mathrm{~mL}$ de-ionized water and mixed with $0.14 \mathrm{~g}$ of 1,3,5-benzenetricarboxylic acid $\left(\mathrm{H}_{3} \mathrm{BTC}\right)$ dissolved in $5 \mathrm{~mL}$ ethanol. The resulting solution was stirred for $30 \mathrm{~min}$ at room temperature, then heated at $383 \mathrm{~K}$ for $18 \mathrm{~h}$ in a teflon-lined stainless steel bomb. After cooling to room temperature, the product was isolated from the solution as a blue powder following centrifugation, washed three times with ethanol, and then dried at $130{ }^{\circ} \mathrm{C}$ for $12 \mathrm{~h}$.

\subsubsection{Synthesis of Cu-BTC Nanocrystals}

$\mathrm{Cu}$-BTC nanocrocrystals was synthesized following the procedure of [49]. Briefly, $0.104 \mathrm{~g}$ of $\mathrm{H}_{3} \mathrm{BTC}$ was dissolved in a solution of $4 \mathrm{~mL}$ dimethylformamide (DMF) and $2 \mathrm{~mL}$ ethanol and then added to $3 \mathrm{~mL}$ of an aqueous solution of $0.099 \mathrm{~g}$ cupric acetate dihydrate. Then, the reaction mixture was ultrasonicated continuously for $5 \mathrm{~min}$ at a frequency of $40 \mathrm{KHz}$. After the ultrasonic irradiation, the resulting blue powder was isolated from the solution and then dried by the same manner as described above for the $\mathrm{Cu}$-BTC microcrystals.

\subsection{Fabrication of the Cu-BTC/CNTs Modified GC Electrode}

CNTs, Cu-BTC microcrystals and Cu-BTC nanocrystals were cast onto GC electrode surfaces. They were first dispersed in $\mathrm{DMF}$ at a concentration of $1 \mathrm{mg} \mathrm{mL}^{-1}$ in an ultrasonic bath. The dispersions of $\mathrm{Cu}$-BTCs are shown in Fig. 1. As can be seen from this figure, due to a higher particle weight of $\mathrm{Cu}$-BTC microcrystals, they settle in the suspension very much sooner than $\mathrm{Cu}$-BTC nanocrystals that form a colloidal suspension. Prior to modification, the bare GC electrode surface was polished with $0.05 \mu \mathrm{m} \alpha-\mathrm{Al}_{2} \mathrm{O}_{3}$, and then rinsed with distilled water. To prepare CNTs modified GC electrode, $2 \mu \mathrm{L}$ of CNT suspension was cast onto the electrode surface with a micro-syringe pipette and its solvent was then allowed to evaporate under an infrared lamp.

In order to prepare Cu-BTC modified GC electrodes, $2 \mu \mathrm{L}$ of $\mathrm{Cu}$-BTC microcrystals or Cu-BTC nanocrystals suspensions were placed onto the CNTs modified GC electrode surface following dryness under infrared lamp, designated as Cu-BTC (micro)/CNTs modified or Cu-BTC (nano)/CNTs modified GC electrodes, respectively.

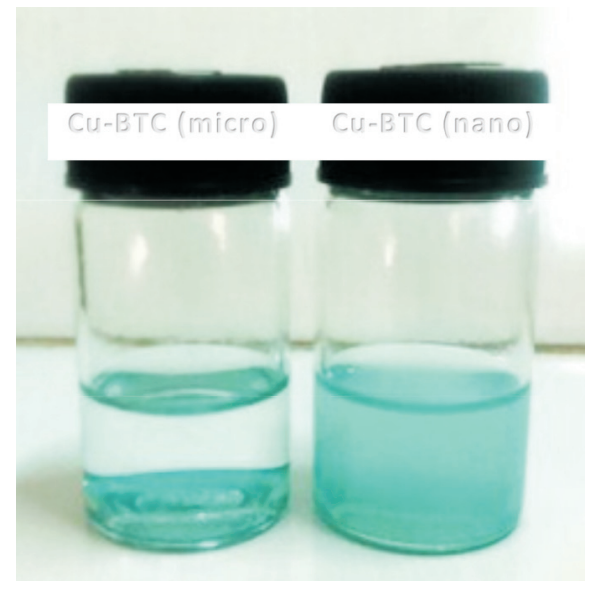

Figure $1 \mathrm{Cu}$-BTC microcrystals and Cu-BTC nanocrystals dispersions in DMF.

\section{Results and Discussion}

\subsection{Morphological Characterization of $\mathrm{Cu}-\mathrm{BTC}$}

The SEM images shown in Fig. 2A and and Fig. 2B illustrate the crystal morphologies of the Cu-BTC prepared using hydrothermal and ultrasonic methods, respectively. As can be seen from Fig. 2A, the Cu-BTC crystals obtained under conventional hydrothermal method show a very larger size range $(20-40 \mu \mathrm{m})$ than those synthesized using ultrasonic method (40-100 nm). These results are consistent with those reported previously using traditional hydrothermal ${ }^{48}$ and using ultrasonic methods. ${ }^{49}$ Fig. $2 \mathrm{C}$ shows a SEM image from the surface of $\mathrm{Cu}-\mathrm{BTC}$ (nano)/CNTs modified GC electrode. One of The MOF nanoparticles, which settled on the wall of CNTs is indicated by the white dashed lines in this figure. 

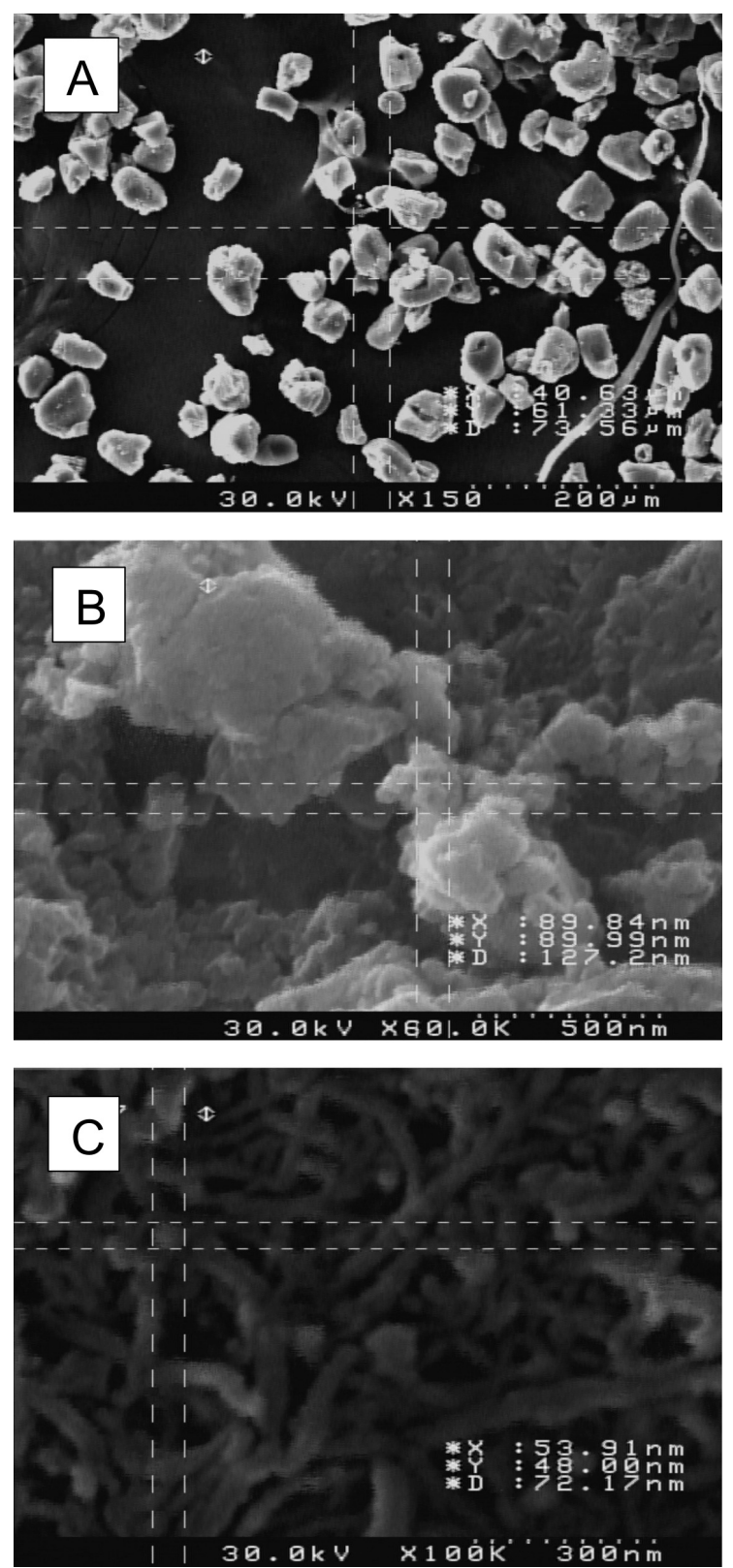

Figure 2 Typical SEM images from the Cu-BTC (micro) powder, Cu-BTC (nano) powder, and the surface of Cu-BTC (nano)/CNTs modified GC electrode.

\subsection{Electrochemical Characteristics of $\mathrm{Cu}-\mathrm{BTC}$ (Nano)/CNTs} and Cu-BTC Micro/CNTs Modified GC Electrodes

Cyclic voltammograms of metformin on a bare GC electrode (2), Cu-BTC (micro) modified GC (3), Cu-BTC (nano) modified GC (4), CNTs modified GC (5), Cu-BTC (micro)/CNTs modified GC (6), and Cu-BTC (nano)/CNTs modified GC (7) electrodes are shown in Fig. 3 and the electrochemical results are summarized in Table 1 ease of comparison.

The bare GC electrode shows a very low electrode activity toward metformin. The anodic peak potential $\left(E_{\mathrm{p}}\right)$ of metformin appears at about $0.64 \mathrm{~V}$ on Cu-BTC (nano) modified GC and on $\mathrm{CNTs}$ modified GC at $0.64 \mathrm{~V}$. At the same time, the anodic peak of metformin on Cu-BTC (nano)/CNTs modified GC appears at $0.59 \mathrm{~V}$ with a significantly enhanced peak current $\left(I_{\mathrm{p}}\right)$ (Fig. 3 and Table 1), which indicates an enhanced electron-transfer rate on the modified electrode. This is due to the synergistic effect from both the high conductivity and the large surface area of the CNT, along with the electron mediating action of $\mathrm{Cu}^{2+}$ ions in the MOF

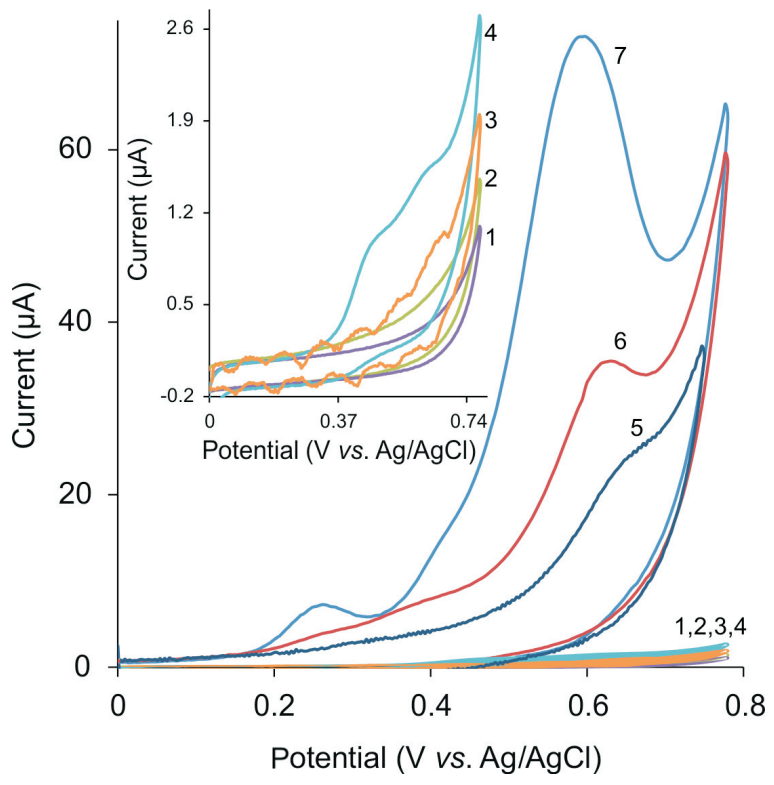

Figure 3 Cyclic voltammograms recorded at GC $(1,2), \mathrm{Cu}-\mathrm{BTC}$ (micro) modified GC (3), Cu-BTC (nano) modified GC (4), CNTs modified GC (5), Cu-BTC (micro)/CNTs modified GC (6), and Cu-BTC (nano)/CNTs modified GC (7) electrodes in (1) the supporting electrolyte solution $(0.1 \mathrm{M} \mathrm{KOH})$ and after $(2,3,4,5,6,7)$ addition of $20 \mu \mathrm{M}$ metformin. Scan rate $100 \mathrm{mV} \mathrm{s}^{-1}$

structure. ${ }^{50}$ Moreover, a high affinity of the MOF to the metformin molecules due to a strong chelating action of metformin toward the $\mathrm{Cu}^{2+}$ ions of the MOF framework together with a high surface area of the MOF can provide more active adsorption sites and electrocatalytic reaction centers, and thereby increase the sensing performance and electrocatalytic effects of the fabricated modified electrode.

A lower value of $E_{\mathrm{p}}(0.59 \mathrm{~V})$ and a significantly higher value of $I_{\mathrm{p}}$ $(73 \mu \mathrm{A})$ at the Cu-BTC (nano)/CNTs modified GC compared to Cu-BTC (micro)/CNTs modified GC electrode $\left(E_{\mathrm{p}} 0.63, I_{\mathrm{p}} 35 \mu \mathrm{A}\right)$ as well as Cu-BTC (nano) modified GC $\left(E_{\mathrm{p}} 0.64, I_{\mathrm{p}} 1.3 \mu \mathrm{A}\right)$ compared to Cu-BTC (micro) modified GC electrodes $\left(E_{\mathrm{p}} 0.69, I_{\mathrm{p}}\right.$ $0.73 \mu \mathrm{A}$ ) indicates clearly with the lower crystal size of MOF, the electrocatalytic performances of the modified electrodes is higher.

The scan rate $(v)$ dependence of cyclic voltammograms for the $\mathrm{Cu}-\mathrm{BTC}$ (nano)/CNTs modified GC electrode toward the oxidation of metformin was also explored (Fig. 4). At the $v$ between 25 and $250 \mathrm{mV} \mathrm{s}^{-1}$, the slope of about 1.0 for the double logarithmic plots of the $I_{\mathrm{p}} v s . v$ indicates that the limiting current is controlled by adsorption process.

As illustrated in Fig. 5, considering the dimensions of the optimized structure of the metformin molecules that can be embedded into a presumptive ball of about $13 \mathrm{~A}^{\circ}$ diameter that fits the larger pores of $\mathrm{Cu}-\mathrm{BTC}{ }^{51}$ the framework structure has a high ability to absorb and accumulate the metformin molecules on the electrode surface.

This property along with the nanometer sized crystals of MOF,

Table 1 Comparison of analytical data at different electrodes.

\begin{tabular}{lcc} 
Electrode & $E_{\mathrm{p}} / \mathrm{V} v s . \mathrm{Ag} / \mathrm{AgCl}$ & $I_{\mathrm{p}} / \mu \mathrm{A}$ \\
\hline Bare GC electrode & $\sim 0.71$ & 0.31 \\
Cu-BTC (micro) modified GC & 0.69 & 0.73 \\
Cu-BTC (nano) modified GC & 0.64 & 1.30 \\
CNTs modified GC & 0.64 & 25.2 \\
Cu-BTC (micro)/CNTs modified GC & 0.63 & 35.10 \\
Cu-BTC (nano)/CNTs modified GC & 0.59 & 73.23 \\
\hline
\end{tabular}




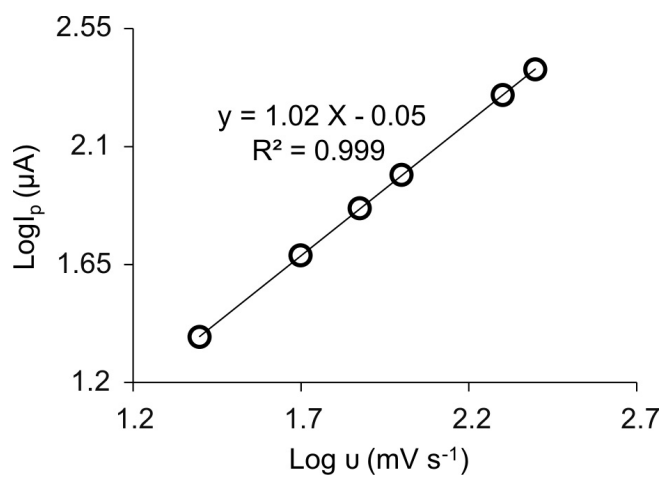

Figure 4 Double logarithmic plot of peak current $\left(I_{\mathrm{p}}\right)$ versus scan rate $(v)$.

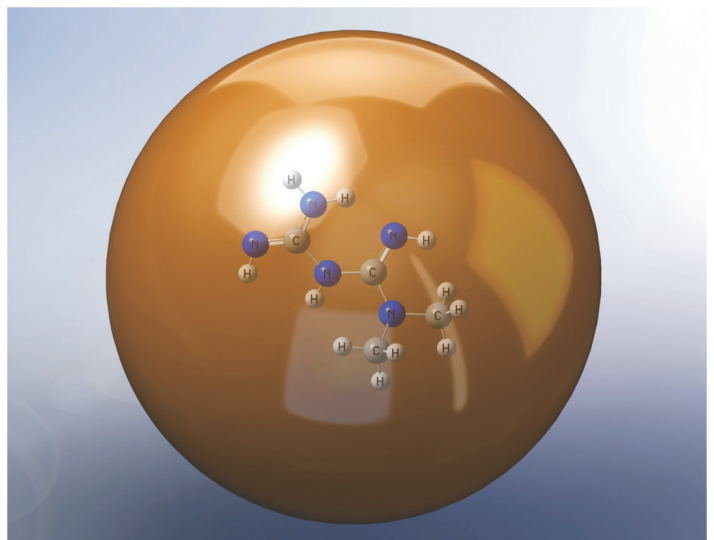

Figure 5 A ball-and-spoke drawings of the metformin molecule superimposed schematically on a $13 \mathrm{~A}{ }^{\circ}$ diameter ball that fits into the larger pores of $\mathrm{Cu}-\mathrm{BTC} \mathrm{MOF}$.

when accompanied with the large surface area and high electrocatalytic activity of the CNT, provides a high sensing performance and electrode sensitivity.

\subsection{Effect of $\mathrm{pH}$}

The $\mathrm{pH}$ effect on the electro-oxidation of metformin was studied in solutions of different $\mathrm{pH}$ values from 5 to 9 . Fig. 6 indicates that the solution $\mathrm{pH}$ has a significant influence on the electro-oxidation of metformin at the Cu-BTC (nano)/CNTs

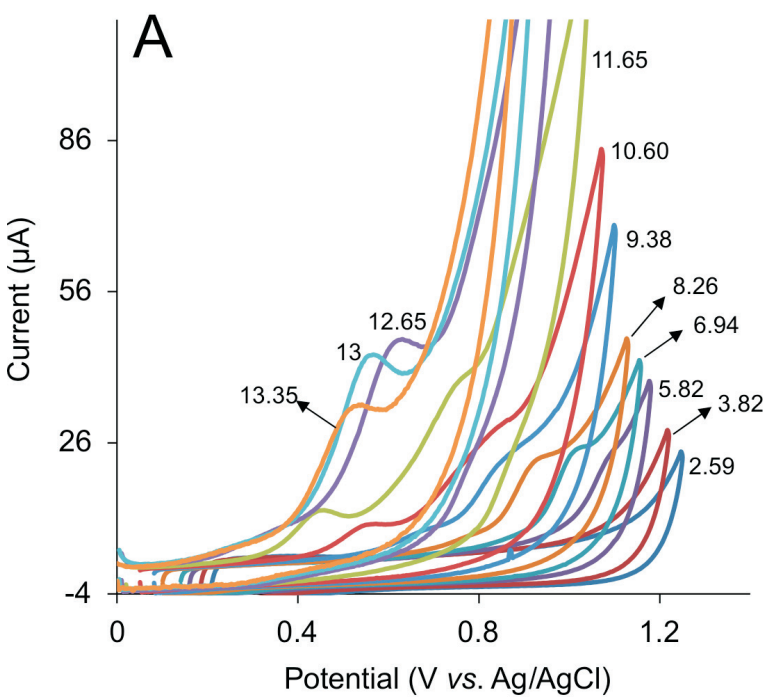

modified GC electrode and protons have taken part in the electrode reaction processes.

As it can be seen from Fig. 6, the $E_{\mathrm{p}}$ value shifts negatively with the increase of the solution $\mathrm{pH}$ so that in the $\mathrm{pH}$ range of $5.82-11.65$, the slope of the linear regression line through the data points $\left(-0.053 \mathrm{mV} \mathrm{pH}^{-1}\right)$, which is very close to the theoretical value of $-0.059 \mathrm{mV} \mathrm{pH}^{-1}$, is consistent with the mechanism proposed for the metformin electro-oxidation based on the equal numbers of electrons and protons..$^{29,50}$ The two linear regions of the $E_{\mathrm{p}}$ vs. $\mathrm{pH}$ plot intersect at about 11.65 (Fig. 6), which are close to the $\mathrm{pK}_{\mathrm{a} 2}$ value (11.5) of metformin. ${ }^{52}$

As can be seen from Fig. 6 , the $I_{\mathrm{p}}$ increased with raising the solution $\mathrm{pH}$ so that the greatest $I_{\mathrm{p}}$ value was obtained in the $\mathrm{pH}$ range of about 12.5-13.5. Approaching $\mathrm{pH}$ to $\mathrm{pK}_{\mathrm{a} 2}$ value, the progressive deprotonation of positively charged metformin molecules that causes a reduction in their repulsive interactions with the electrode surface during the anodic change of potential or with $\mathrm{Cu}^{2+}$ ions of the MOF framework results in increased easily of oxidation. As the best result was obtained at $\mathrm{pH} 13.0$ $(\mathrm{KOH} 0.1 \mathrm{M})$, this $\mathrm{pH}$ value was used for all electrochemical measurements.

\subsection{Optimization of the Amount of CNT and Cu-BTC (Nano)}

The cyclic voltammetry experiments were conducted at the GC electrode modified with different amount of CNT $\left(1 \mathrm{mg} \mathrm{mL}^{-1}\right)$ dispersion. The relationship between the $I_{\mathrm{p}}$ value and the volume of CNT dispersion used for the electrode modification was illustrated in Fig. 7. As the signal was not improved above $2 \mu \mathrm{L}$, this volume was chosen as an optimum volume of the CNT dispersion.

The amount of Cu-BTC (nano) was also optimized by applying different amount of Cu-BTC (nano) dispersion $\left(1 \mathrm{mg} \mathrm{mL}^{-1}\right)$ on the CNTs modified GC electrode. From Fig. 7, it can be seen that the $I_{\mathrm{p}}$ value first rapidly increases with increasing the volume of Cu-BTC (nano) dispersion up to about $2 \mu \mathrm{L}$, and then slightly decreases with the higher dispersion volume (Fig. 7). This should be attributed to an increase in the electrical resistance of the electrode due to the excess of Cu-BTC (nano). The volume of the Cu-BTC (nano) dispersion chosen in the detection of metformin was $2 \mu \mathrm{L}$.

\subsection{Influence of Accumulation Time}

Figure 8 shows the voltammograms obtained at the Cu-BTC

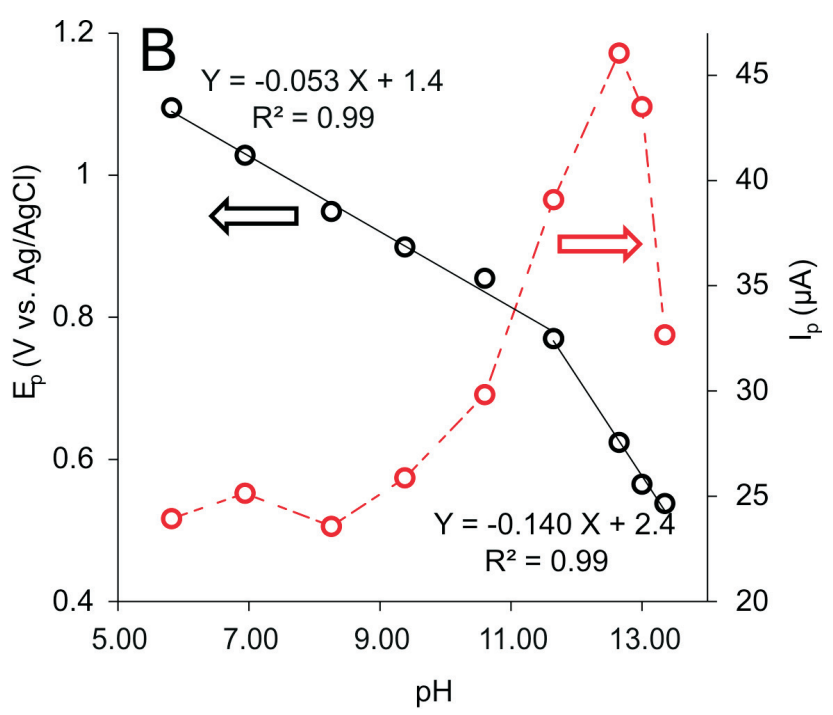

Figure 6 (A) Cyclic voltammograms at the Cu-BTC (nano)/CNTs modified GC electrode (scan rate $100 \mathrm{mV} \mathrm{s}^{-1}$ ) in solutions containing $20 \mu \mathrm{M}$ metformin at different $\mathrm{pH}$ values. (B) The corresponding plots of the $I_{\mathrm{p}}$ and $E_{\mathrm{p}}$ versus $\mathrm{pH}$. The solutions with the $\mathrm{pH}$ values from 2.59 to 12.65 were Britton-Robinson buffers $(0.1 \mathrm{M})$ and the solutions with the higher $\mathrm{pH}$ values are prepared from $\mathrm{KOH}$. 


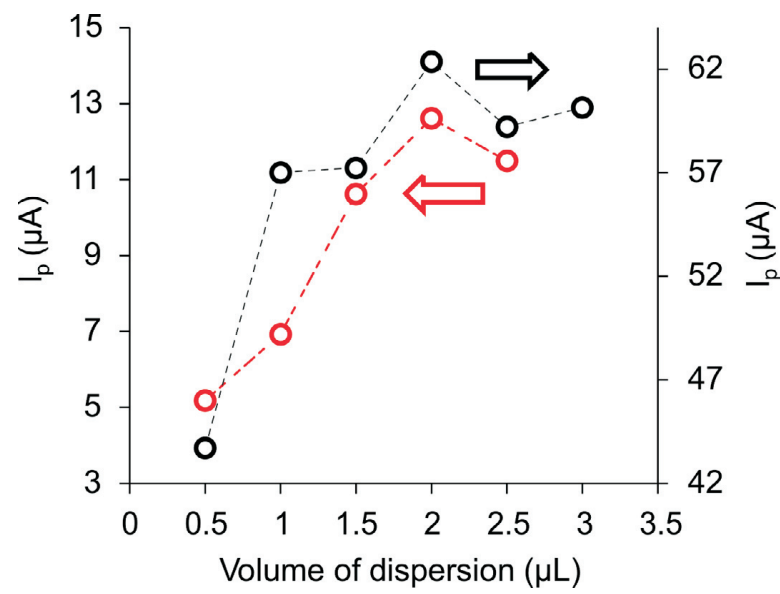

Figure 7 Plot of $I_{\mathrm{p}}$ versus the (red line) volume of CNT dispersion used for the modification of GC electrode and the (black line) the volume of $\mathrm{Cu}-\mathrm{BTC}$ (nano) dispersion used for the modification of CNTs modified GC electrode.

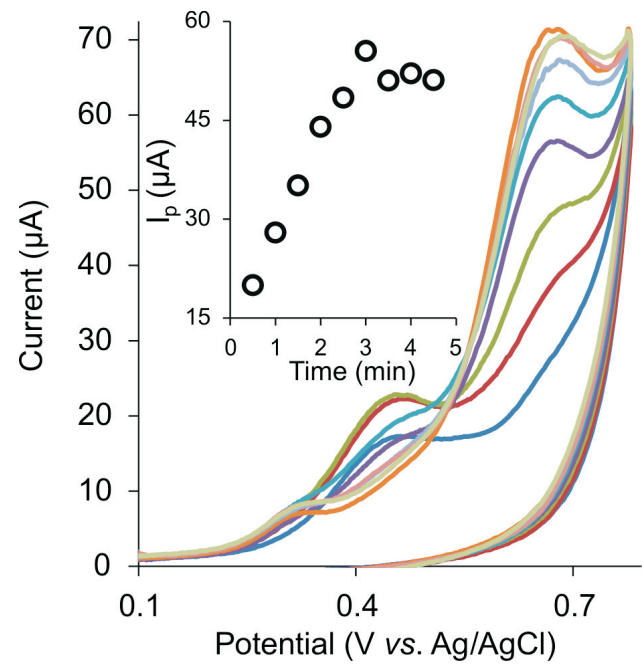

Figure 8 Cyclic voltammograms obtained at the Cu-BTC (nano)/CNTs modified GC electrode (scan rate $100 \mathrm{mV} \mathrm{s}^{-1}$ ) for $10 \mu \mathrm{M}$ metformin in $0.1 \mathrm{M} \mathrm{KOH}$ solution at different accumulation time. The inset shows the corresponding plot of $I_{\mathrm{p}}$ versus accumulation time.

(nano)/CNTs modified GC electrode at different accumulation time and the plot of the $I_{\mathrm{p}}$ value vs. the accumulation time is also shown in the inset of this figure.

It can be seen that the $I_{\mathrm{p}}$ rises rapidly by increasing the preconcentration time up to $3 \mathrm{~min}$, and after that tends to a constant value. The accumulation time chosen for further experiment was $3 \mathrm{~min}$.

\subsection{Analytical Figures of Merit}

The effect of the varying concentration of metformin on $I_{\mathrm{p}}$ at the Cu-BTC (nano)/CNTs modified GC electrode at the optimized experimental conditions is shown in Fig. 9.

The $I_{p}$ values increased linearly by increase the metformin concentration in the range of $0.50-25.00 \mu \mathrm{M}$. The $I_{\mathrm{p}}$ level off at $25.00 \mu \mathrm{M}$, probably due to saturation adsorption limitations. The correlation coefficient (0.995) of the linear least squares fit of the calibration curve indicates that the regression line is fitted very well with the experimental data (Fig. 9). The detection limit (signal to noise of 3 ) was calculated as $0.12 \mu \mathrm{M}$ and the sensitivity was $1.65 \mu \mathrm{A}_{\mu} \mathrm{M}^{-1}$. These analytical parameters, as can be seen from Table 2, are comparable and in most cases better than those reported by other researchers using other modified electrodes.

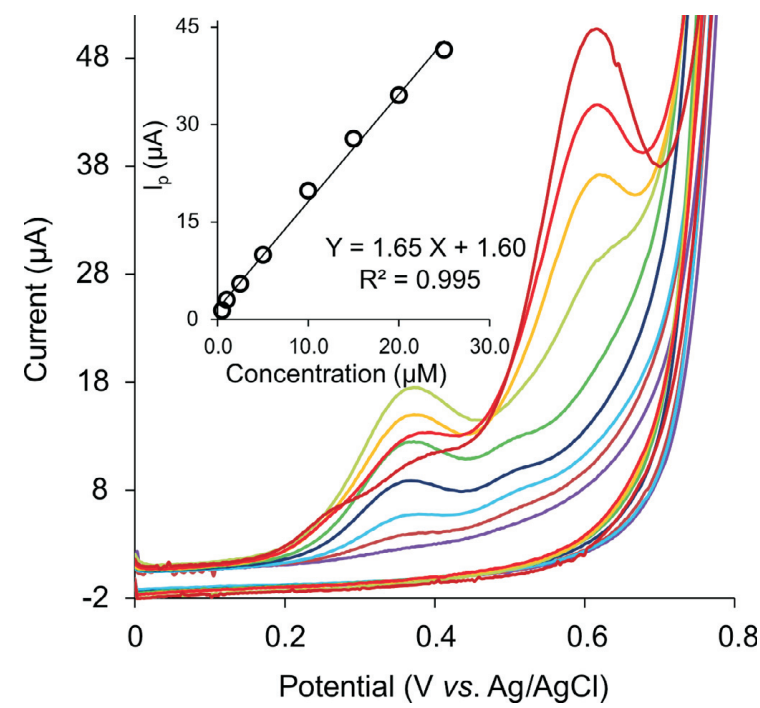

Figure 9 Dependence of the cyclic voltammetric response at the $\mathrm{Cu}-\mathrm{BTC}$ (nano)/CNTs modified GC electrode on metformin concentration in $0.1 \mathrm{M} \mathrm{KOH}(\mathrm{pH} 13)$. Concentrations from bottom to top are $0.00,0.50$, $1.00,2.5,5.00,10.00,15.00,20.00$ and 25.00, $\mu \mathrm{M}$. Inset plot A shows the corresponding calibration graph.

Especially the modified electrode shows a significantly higher sensitivity compared to the other electrodes.

Figure 10 shows 7 replicate voltammograms obtained at the Cu-BTC (nano)/CNTs modified GC electrode in a solution containing $10 \mu \mathrm{M}$ metformin, which can provide an estimate of the repeatability of the modified electrode. The GC electrode surface has been modified freshly for each measurement. The precision of the described method in terms of relative standard deviation of the $I_{\mathrm{p}}$ values was found to be $4.8 \%$, which indicates excellent electrochemical response repeatability of the modified electrodes.

\subsection{Application}

In order to demonstrate the applicability of the proposed method for the determination of metformin in pharmaceutical formulations, three commercial medicinal samples containing metformin were studied. The medicinal samples were Brot ${ }^{\circledR}$ (Medochemi Ltd., Cyprus), Hexal ${ }^{\circledR}$ (Hexal AG., Germany) and Glucophage $^{\circledast}$ (Merck Santé S.A.S., France). The tablets were powdered and homogenized. $0.015 \mathrm{~g}$ of this powder was weighed and dissolved in the supporting electrolyte solution $(0.1 \mathrm{M} \mathrm{KOH})$ and then transferred quantitatively into a $100 \mathrm{~mL}$

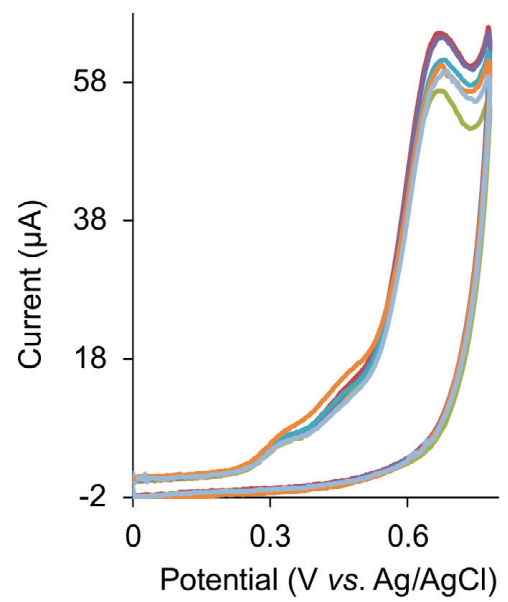

Figure 10 Cyclic voltammograms recorded successively at the Cu-BTC (nano)/CNTs modified GC electrodes (scan rate $100 \mathrm{mV} \mathrm{s}^{-}$) for $10 \mu \mathrm{M}$ metformin in $0.1 \mathrm{M} \mathrm{KOH}$ solution. 
Table 2 Comparison of the proposed voltammetric method with previously reported electrochemical methods for determination of metformin.

\begin{tabular}{|c|c|c|c|c|c|}
\hline Methods & Electrode & $\begin{array}{l}\text { Linear dynamic } \\
\text { range/ } \mu \mathrm{M}\end{array}$ & $\begin{array}{c}\text { Limit of } \\
\text { detection } / \mu \mathrm{M}\end{array}$ & $\begin{array}{l}\text { Sensitivity } \\
/ \mu \mathrm{A} \mu \mathrm{M}^{-1} \mathrm{~cm}^{-2}\end{array}$ & Ref. \\
\hline $\begin{array}{l}\text { Differential pulse } \\
\text { voltammetry (DP }\end{array}$ & Pyrogallol modified carbon paste (CP) & $0.8-6$ & 0.0663 & - & 27 \\
\hline Cyclic voltammetry & $\mathrm{BiVO}_{4}$ modified CP & $700-6000$ & 400 & 0.0037 & 28 \\
\hline DPV & $\begin{array}{l}\text { Copper-loaded activated } \\
\text { charcoal modified CP }\end{array}$ & $0.05-60$ & 0.009 & 20.62 & 29 \\
\hline $\begin{array}{l}\text { Second-order derivative } \\
\text { single sweep voltammetry }\end{array}$ & $\begin{array}{l}\text { Molecular wires containing copper(II)/ } \\
\text { multi-walled CNT paste }\end{array}$ & $0.9-50$ & 0.65 & 0.28 & 30 \\
\hline Amperometry & $\begin{array}{l}\text { Nickel oxide nanotubes- } \\
\text { carbon microparticles/Nafion } \\
\text { modified CP }\end{array}$ & $4.0-63$ & 0.45 & 2.10 & 31 \\
\hline $\begin{array}{l}\text { Second-order derivative single } \\
\text { sweep voltammetry }\end{array}$ & Multi-walled CNT paste & $0.2-10$ & 0.067 & 0.23 & 50 \\
\hline Cyclic voltammetry & $\begin{array}{l}\mathrm{Cu}-\mathrm{BTC}(\text { nano)/CNTs } \\
\text { modified GC }\end{array}$ & $0.50-25.00$ & 0.12 & 82.5 & This work \\
\hline
\end{tabular}

flask and diluted to volume. $5 \mathrm{~mL}$ of this solution was diluted to $100 \mathrm{~mL}$ with the supporting electrolyte solution and $5 \mathrm{~mL}$ of this solution was added to the measurement cell. The calibration curve method was made simply with the working solution for determination of the content of metformin in the samples. The results obtained in the analysis of four replicates from each sample are summarized in Table 3 and show a satisfactory agreement with the labelled amounts.

Table 3 Determination of metformin in pharmaceutical preparations using Cu-BTC (nano)/CNTs modified GC electrodes.

\begin{tabular}{lccc}
\hline Sample & Stated content & Determined content & Error/\% \\
\hline Brot $^{\circledR}$ & $500 \mathrm{mg} \mathrm{tablet}^{-1}$ & $3 / 98$ & $1 / 24$ \\
Hexal $^{\circledast}$ & $500 \mathrm{mg} \mathrm{tablet}^{-1}$ & $5 / 263$ & $4 / 72$ \\
Glucophage $^{\circledR}$ & $500 \mathrm{mg} \mathrm{tablet}^{-1}$ & $4 / 914$ & $-1 / 007$ \\
\hline
\end{tabular}

\subsection{Comparison with Other Methods}

Some analytical data reported for determination of metformin by methods based on chromatography or spectrophotometry are compared with the proposed method in Table 4. As is clear from Table 4, compared to the other methods reported, the proposed method shows a detection limit and linear dynamic range comparable or in some cases slightly better although it should be noted that the high sensitivity, rapid analysis time, simplicity and low cost of analysis are the main advantages of the electrochemical voltammetric method over the chromatography-based or spectroscopy-based methods.

\section{Conclusion}

In this paper, the Cu-BTCs were prepared and it was shown that their composites with multiwall CNT can be used as a suitable and effective electrode modifier for metformin determination in aqueous solution. It was shown that the MOF crystallite size has a significant influence on the electrocatalytic performance of the modified electrode so that the Cu-BTC crystals with nanometer dimensions, synthesized by the ultrasonic method, indicate higher electrocatalytic activity compared to those synthesized with conventional solvothermal method with micrometer-sized crystallite. The modified electrode was prepared by a simple procedure and showed good reproducibility. Analysis of metformin by voltammetric technique was performed in comparison to the other reported methods (Tables 2 and 4) with a long linear dynamic range of $0.50-25.00 \mu \mathrm{M}$ and a low detection limit of $0.12 \mu \mathrm{M}$. The proposed modified electrode used as a sensitive, fast and simple voltammetric sensor for metformin determination in real pharmaceutical samples.

Table 4 Comparison of analytical data for metformin determination.

\begin{tabular}{|c|c|c|c|}
\hline Technique & Linear dynamic range $/ \mu \mathrm{g} / \mathrm{mL}$ & Limit of detection $/ \mu \mathrm{g} / \mathrm{mL}$ & Ref. \\
\hline Capillary electrophoresis & $0.25-3.5$ & & 2 \\
\hline Ion pair solid phaseextraction and ion pair liquid chromatography & $0.05-2$ & 0.003 & 5 \\
\hline High performance liquid chromatography (HPLC) & $0.02-4$ & & 6 \\
\hline HPLC & $0.0625-8$ & 0.04 & 7 \\
\hline HPLC & $15-45$ & & 9 \\
\hline LC-MS/MS & $0.01214-1.20750$ & & 10 \\
\hline HPLC & $10-30$ & & 11 \\
\hline LC-MS/MS & $0.001-2$ & 0.000250 & 12 \\
\hline HPLC & $0.2-2.5$ & 0.020 & 13 \\
\hline Spectrophotometry & $2-12$ & 0.24 & 18 \\
\hline Spectrophotometry & $4-26$ & & 20 \\
\hline Spectrophotometry & $1-10$ & 0.082 & 21 \\
\hline Spectrophotometry & $8-18$ & & 22 \\
\hline Spectrophotometry & 2-10 & & 23 \\
\hline Electrochemistry (voltammetry) & $0.078-3.91$ & 0.019 & This work \\
\hline
\end{tabular}




\section{References}

1 A. Scheen and P. Lefebvre, Oral antidiabetic agents: a guide to selection, Drugs, 1998, 55, 225-236.

2 J.Z. Song, H.F. Chen, S.J. Tian and Z.P. Sun, Determination of metformin in plasma by capillary electrophoresis using field-amplified sample stacking technique, J. Chromatogr. B, 1998, 708, 277-283.

3 I.I. Hamdan, A.K.B. Jaber and A.M. Abushoffa, Development and validation of a stability indicating capillary electrophoresis method for the determination of metformin hydrochloride in tablets, J. Pharm. Biom. Anal., 2010, 53, 1254-1257.

4 F. Tache, V. David, A. Farca and A. Medvedovici, HPLC-DAD determination of metformin in human plasma using derivatization with p-nitrobenzoyl chloride in a biphasic system, Microcem. J., 2001, 68, 13-19.

5 S. AbuRuz, J. Millership and J. MaElnay, Determination of metformin in plasma using a new ion pair solid phase extraction technique and ion pair liquid chromatography, J. Chromatogr. B, 2003, 798, 203-209.

6 M. Zhang, G.A. Moore, M. Lever, S.J. Gardiner, C.M. J. Kirkpatrick and E.J. Begg, Rapid and simple high-performance liquid chromatographic assay for the determination of metformin in human plasma and breast milk, J. Chromatogr. B, 2001, 766, 175-179.

7 K.H. Yuen and K.K. Peh, Simple high-performance liquid chromatographic method for the determination of metformin in human plasma, J. Chromatogr. B, 1998, 710, 243-246.

8 M.S. Lennard, C. Casey, G.T. Tucker and H.F. Woods, Determination of metformin in biological samples, Br. J. Clin. Pharmacol., 1978, 6, 183-185.

9 S.K. Konidala and P. Hemanth, A simple and validated RP-HPLC method for the simultaneous determination of vildagliptin and metformin in bulk and pharmaceutical dosage forms, Int. J. Curr. Pharm. Res., 2014, 6, 31-35.

10 S.R. Polagani, N.R. Pilli, R. Gajula and V. Gandu, Simultaneous determination of atorvastatin, metformin and glimepiride in human plasma by LC-MS/MS and its application to a human pharmacokinetic study, J. Pharm. Anal., 2013, 3, 9-19.

11 F. Al-Rimawi, Development and validation of an analytical method for metformin hydrochloride and its related compound (1-cyanoguanidine) in tablet formulations by HPLC-UV, Talanta, 2009, 79, 1368-1371.

12 Y. Wang, Y. Tang, J. Gu, J.P. Fawcett and X. Bai, Rapid and sensitive liquid chromatography-tandem mass spectrometric method for the quantitation of metformin in human plasma, J. Chromatogr. B, 2004, 808, 215-219.

13 A. Zarghi, S.M. Foroutan, A. Shafaati and A. Khoddam, Rapid determination of metformin in human plasma using ion-pair HPLC, J. Pharm. Biomed. Anal., 2003, 31, 197-200.

14 H.H. Gadape and K.S. Parikh, Quantitative determination and validation of metformin hydrochloride in pharmaceutical using quantitative nuclear magnetic resonance spectroscopy, E -J. Chem., 2011, 8, 767-781.

15 S.S.M. Hassan, W.H. Mahmoud, M.A.F. Elmosallamy and A.M. Othman, Determination of metformin in pharmaceutical preparations using potentiometry, spectrofluorimetry and UV-visible spectrophotometry, Anal. Chim. Acta, 1999, 378, 299-311.

16 M.F. Abdel-Ghany, O. Abdel-Aziz, M.F. Ayad and M.M. Tadros, Validation of different spectrophotometric methods for determination of vildagliptin and metformin in binary mixture, Spectrochim. Acta, 2014, 125, 175-182.

17 S.M. Riad, M.R. Rezk, G.Y. Mahmoud and A.E. Abdel-Aleem, Spectrophotometric determination of sitagliptin and metformin in their pharmaceutical formulation, Int. J. Comprehe. Pharm., 2012, 3, 1-4.

18 R.I. El-Bagary, E.F. Elkady and B.M. Ayoub, Spectroflourometric and spectrophotometric methods for the determination of sitagliptin in binary mixture with metformin and ternary mixture with metformin and sitagliptin alkaline degradation product, Int. J. Biomed. Sci., 2011, 7, 62-69.

19 M.R. Sohrabi, N. Kamali and M. Khakpour, Simultaneous spectrophotometric determination of metformin hydrochloride and glibenclamide in binary mixtures using combined discrete and continuous wavelet transforms, Anal. Sci., 2011, 27, 1037-1041.

20 G. Mubeen, K. Noor and M.N. Vimala, Spectrophotometric method for estimation of metformin hydrochloride, Int. J. Chem. Tech. Res., 2010, 2, 1186-1187.
21 M.S. Arayne, N. Sultana, M.H. Zuberi and F.A. Siddiqui, Spectrophotometric quantitation of metformin in bulk drug and pharmaceutical formulations using multivariate technique, Indian J. Pharm. Sci., 2009, 71, 331-335.

22 G. Mubeen and K. Noor, Spectrophotometric method for analysis of metformin hydrochloride, Indian J. Pharm. Sci., 2009, 71, 100-102

23 P.S. Sudarshan and C.G. Bonde, Development and validation of analytical method for simultaneous estimation of glibenclamide anmin $\mathrm{HCl}$ in bulk and tablets using UV-visible spectroscopy, Int J. Chem. Tech. Res., 2009, 1, 905-909.

24 S. Ashour and R. Kabbani, Direct spectrophotometric determination of metformin hydrochloride in pure form and in drug formulation, Anal. Lett., 2003, 36, 361-370.

25 J.M. Calatayud, P.C. Falco and M.C.P. Marti, Metformin and moroxidine determination with Cu (II), Anal. Lett., 1985, 18, 1381-1390.

26 I.H.I. Habib and M.S. Kamel, Near infra-red reflectance spectroscopic determination of metformin in tablets, Talanta, 2003, 60, 185-190.

27 A.K. Attia, W.M. Salem and M.A. Mohamed, Voltammetric assay of metformin hydrochloride using pyrogallol modified carbon paste electrode, Acta Chim. Slov., 2015, 62, 588-594.

28 L.M. Blanco Jerez, U.M. García-Pérez, P. Zambrano-Robledo and J. Hernández-Moreira, Carbon paste electrode modified with BiVO4 to sense metformin, Int. J. Electrochem. Sci., 2014, 9, 4643-4652.

29 M.B. Gholivand and L. Mohammadi-Behzad, Differential pulse voltammetric determination of metformin using copper-loaded activated charcoal modified electrode, Anal. Biochem., 2013, 438, 53-60.

30 X.j. Tian, J.f. Song, X.j. Luan, Y.y. Wang and Q.z. Shi, Determination of metformin based on amplification of its voltammetric response by a combination of molecular wire and carbon nanotubes, Anal. Bioanal. Chem., 2006, 386, 2081-2086.

31 N. Sattarahmady, H. Heli and F. Faramarzi, Nickel oxide nanotubescarbon microparticles/Nafion nanocomposite for the electrooxidation and sensitive detection of metformin, Talanta, 2010, 82, 1126-1135.

32 P. Papakonstantinou, R. Kern, L. Robinson, H. Murphy, J. Irvine, E. McAdams and J. McLaughlin, Fundamental electrochemical properties of carbon nanotube electrodes, Fuller. Nanotub. Car. N., 2005, 13, 91-108.

33 A. Merkoc, M. Pumera, X. Llopis, B. Pe rez, M. del Valle and S. Alegret, New materials for electrochemical sensing VI: carbon nanotubes, Trac-Trend Anal. Chem., 2005, 24, 826-838.

34 Q.M. Wang, D.M. Shen, M. Bulow, M.L. Lau, S.G. Deng, F.R. Fitch, N.O. Lemcoff and J. Semanscin, Metallo-organic molecular sieve for gas separation and purification, Micropor. Mesopor. Mater., 2002, 55, 217-230.

35 H. Zhou and S. Kitagawa, Metal-organic frameworks (MOFs), Chem. Soc. Rev., 2014, 43, 5415-5418.

36 B. Yuan, R. Zhang, X. Jiao, J. Li, H. Shi and D. Zhang, Amperometric determination of reduced glutathione with a new Co-based metalorganic coordination polymer modified electrode, Electrochem. Commun., 2014, 40, 92-95.

37 K.F. Babu, M.A. Kulandainathan, I. Katsounaros, L. Rassaei, A.D. Burrows, P.R. Raithby and F. Marken, Electrocatalytic activity of BasoliteTMTM F300 metal-organic-framework structures, Electrochem. Commun., 2010, 12, 632-635.

38 H. Hosseini, H. Ahmar, A. Dehghani, A. Bagheri, A. Tadjarodi and A.R. Fakhari, A novel electrochemical sensor based on metal-organic framework for electro-catalytic oxidation of L-cysteine, Biosen. Bioelectron., 2013, 42, 426-429.

39 H. Hosseini, H. Ahmar, A. Dehghani, A. Bagheri, A.R. Fakhari and M.M. Amini, Au-SH-SiO2 nanoparticles supported on metal-organic framework (Au-SH-SiO2@ Cu-MOF) as a sensor for electrocatalytic oxidation and determination of hydrazine, Electrochim. Acta. 2013, 88, 301-309.

40 E. Zhou, Y. Zhang, Y. Li and X. He, Cu(II)-Based MOF Immobilized on multiwalled carbon nanotubes: synthesis and application for nonenzymatic detection of hydrogen peroxide with high sensitivity, Electroanalysis, 2014, 26, 2526-2533.

41 Y. Wang, H. Ge, G. Ye, H. Chen and X. Hu, Carbon functionalized metal organic framework/Nafion composites as novel electrode materials for ultrasensitive determination of dopamine, J. Mater. Chem. B, 2015, 3, 3747-3753. 
42 Y. Zhang, X. Bo, C. Luhana, H. Wang, M. Li and L. Guo, Facile synthesis of a Cu-based MOF confined in macroporous carbon hybrid material with enhanced electrocatalytic ability, Chem. Commun., 2013, 49, 6885-6887.

43 X. Wang, Q. Wang, Q. Wang, F. Gao, F. Gao, Y. Yang and H. Guo, Highly dispersible and stable copper terephthalate MOF-graphene oxide nanocomposite for electrochemical sensing application, ACS Appl. Mater. Interfaces., 2014, 6, 11573-11580.

44 J. Zhou, X. Li, L. Yang, S. Yan, M. Wang, D. Cheng, Q. Chen, Y. Dong, P. Liu, W. Cai and C. Zhang, The Cu-MOF-199/single-walled carbon nanotubes modified electrode for simultaneous determination of hydroquinone and catechol with extended linear ranges and lower detection limits, Anal. Chim. Acta., 2015, 899, 57-65.

45 Y. Wang, Y. Wu, J. Xie, H. Ge and X. Hu, Multi-walled carbon nanotubes and metal-organic framework nanocomposites as novel hybrid electrode materials for the determination of nano-molar levels of lead in a lab-on-valve format, Analyst, 2013, 138, 5113-5120.

46 L. Fotouhi and M. Naseri, Recent electroanalytical studies of metal-organic frameworks: a mini-review, Crit. Rev. Anal. Chem., 2015, 17, 1-9.
47 N.A. Khan and S.H. Jhung, Synthesis of metal-organic frameworks (MOFs) with microwave or ultrasound: rapid reaction, phase-electivity, and size reduction, Coord. Chem. Rev., 2015, 285, 11-23.

$48 \mathrm{~J}$. Gascon, S. Aguado and F. Kapteijn, Manufacture of dense coatings of Cu3(BTC)2 (HKUST-1) on a-alumina, Microporous Mesoporous Mater., 2008, 113, 132-138.

49 Z.Q. Li, L.G. Qiu, T. Xu, Y. Wu, W. Wang, Z.Y. Wu and X. Jiang, Ultrasonic synthesis of the microporous metal-organic framework Cu3(BTC)2 at ambient temperature and pressure: an efficient and environmentally friendly method, Mater. Lett., 2009, 63, 78-80.

50 X.J. Tian and J.F. Song, Catalytic action of copper (II) ion on electrochemical oxidation of metformine and voltammetric determination of metformine in pharmace, J. Pharm. Biomed. Anal., 2007, 44, 1192-1196.

51 J.A. Mason, M. Veenstra and J.R. Long, Evaluating metal-organic frameworks for natural gas storage, Chem. Sci., 2014, 5, 32-51.

52 D. Desai, B. Wong, Y. Huang, Q. Ye, D. Tang, H. Guo, M. Huang and P. Timmins, surfactant-mediated dissolution of metformin hydrochloride tablets: wetting effects versus ion pairs diffusivity, J. Pharm. Sci., 2014, 103, 920-926. 